Z. klin. Chem. u. klin. Biochem.

7. Jg., S. 56-59, Januar 1969

\title{
Mikrochemische Zinkbestimmung im Serum und Urin $\left.{ }^{1}\right)$
}

\author{
Von H. H. Hellivege, H. Schmalfuss und D. Goschenhofer \\ Aus der Universitäts-Kinderklinik Hamburg-Eppendorf (Direktor: Prof. Dr. K. H. Scbäfer)
}

(Eingegangen am 7. Oktober 1968)

Es wird eine Mikromethode zur Bestimmung des Serumzinks mitgeteilt, die nur 0,1 $\mathrm{m} /$ Serum pro Bestimmung benötigt. Die Genauigkeit der entwickelten Mikromethode ist der der bekannten Makromethoden zumindest gleichwertig. Eine analoge Methode zur Bestimmung des Urin-Zinkgehaltes wurde entwickelt und ihre Brauchbarkeit festgestellt. Es wurden Normalwerte für alle Altersgruppen der Kindheit bestimmt. Es fand sich in allen Altersgruppen ein Serumzinkspiegel um $112 \mu \mathrm{g} / 100 \mathrm{ml}$.

\section{Microchemical determination of qinc in serum and urine}

A micromethod, requiring only $0.1 \mathrm{~m} /$ serum, is reported for the measurement of serum zinc. The accuracy is at least equal to that of the known macromethods. An analogous method was developed for the determination of zinc in urine and its applicability was demonstrated. Normal values were determined for all juvenile age groups. In all age groups, the serum zinc level was $112 \mu \mathrm{g} / 100 \mathrm{~m} /$.

Bei den gewöhnlich angewandten Methoden zur Zinkbestimmung ergeben sich erhebliche methodische Schwierigkeiten. Deshalb wird die Zinkbestimmung im Gegensatz zur Eisen- und Kupferbestimmung als klinische Untersuchungsmethode noch wenig angewandt.

Bei der vorwiegend benutzten Dithizon-Methode muß im Zweiphàsensystem gearbeitet werden. Dabei wird das Zink aus der wäßr. Phase in die das Nachweisreagenz enthaltende Tetrachlorkohlenstoffphase überführt. Bei den in der Gebrauchslösung vorliegenden Verdünnungen ist das Nachwreisreagenz Dithizon gegen Wärme und Tageslicht sehr empfindlich und ändert bei unsachgemäßer Benutzung durch teilweisen Zerfall seine Farbe in photometrisch meßbarer Größenordnung schon im Zeitraum von einigen Minuten. Darüber hinaus ver- langen die bisher beschriebenen Methoden 1-2 $\mathrm{m} l$ Serum pro Bestimmung, Mengen, die in der Pädiatrie häufig nicht zur Verfügung stehen.

Mit den bekannten Methoden war es daher nicht möglich, die von uns geplanten Untersuchungen des Zinkstoffwechsels bei Frühgeborenen, Neugeborenen und Kleinkindern durchzuführen. Es mußte eine neue mikrochemische Bestimmungsmethode ausgearbeitet werden, bei der nur ein Zehntel bis ein Zwanzigstel der bisher verwandten Serummengen benötigt werden (1). Diese Mikromethode ermöglicht durch die Benutzung kleiner Röhrchen und Gefäße ein schnelles Arbeiten und eine weitgehende Benutzung der Dithizonlösung unter Lichtabschluß.

\section{Methodik}

Prinzip

Nach Freisetzung des Serumzinks mit $1 \mathrm{~N} \mathrm{HCl}$ wird das Eiweiß mit $3 \mathrm{M}$ Trichloressigsäure ausgefällt und abzentrifugiert. $0,1 \mathrm{~m} l$ des klaren Uberstandes werden mit einem Puffer, dessen $\mathrm{pH}$-Wert und Zusätze an Maskierungsmitteln (,Tarnpuffergemisch"), die ausschließliche Reaktion des Nachweisteagenz Dithizon mit Zink garantieren, versetzt. Mit dem Dithizon wird das Zink ausgeschüttelt und als rotes Dithizonat in der Tetrachlorkohlenstoffphase bei einer Wellenlänge von $546 \mathrm{~nm}$ photometrisch gemessen $(2,3)$.

2) Mit Unterstützung der Deutschen Forschungsgemeinschaft.

\section{Arbeitsvorschrift, Serumzinkbestimmung}

Bei der Verarbeitung der Serumproben wurde das Mikroprogramm der Fa. Netheler \& Hinz und das Photometer Eppendorf mit Mikroküvette verwendet.

Gewinnung des Serums: Mit zinkfreien Kanülen wird eine Vene punktiert, der erste Tropfen verworfen, dann etwa $1 \mathrm{~m} /$ Blut (ausreichend für eine Doppelbestimmung) in zinkfreien Polyäthylenröhrchen aufgefangen, $2 \mathrm{Min}$. bei $17000 \mathrm{U}$./Min. zentrifugiert, das Serum mit Marburg-Pipetten mit zinkfreien Spitzen in neue Röhrchen abpipettiert und im Kühlschrank verwahrt.

Verarbeitung des Serums: In je zwei Polyäthylenröhrchen wérden je $100 \mu /$ bidest. Wasser (Leerwert), eingestellte Zinkstandardlösung $(100 \mu \mathrm{g} / 100 \mathrm{~m} /$ Standard) bzw. Serum pipettiert. Pro Röhrchen werden $50 \mu / 1 \mathrm{~N} \mathrm{HCl}$ hinzugegeben, es wird 5 Min. auf dem Rütteltisch geschüttelt, kurz zentrifugiert und der Ansatz 15 Min. stehengelassen. Anschließend werden je $20 \mu l 3 \mathrm{M}$ Trichloressigsäure zugegeben, es wird $5 \mathrm{Min}$. geschüttelt und $2 \mathrm{Min}$. bei $17000 \mathrm{U}$./Min. zentrifugiert. Je $100 \mu l$ des Uberstandes werden in neue Röhrchen pipettiert, darauf $100 \mu l$ Tarnpuffergemisch hinzugegeben. Hierzu kommen jeweils $300 \mu l$ Dithizongebrauchslösung; die Röhrchen werden sofort verschlossen und in einen lichtdichten Kasten verbracht und 20 Min. kräftig geschüttelt. Das Schütteln unter Lichtabschluß ist nötig, da das verdünnte Dithizon unter Lichteinwirkung sehr schnell zerfällt. Zuletzt werden die Phasen durch 2 Min. Zentrifugieren bei 17000 U./Min. getrennt. Die untere Tetrachlorkohlenstoffphase mit dem Zinkdithizonat wird vorsichtig in die Mikroküvette überpipettiert (je $200 \mu l$ ) und im abgedunkelten Raum photometriert.

Bestimmung der Zinkwerte: Wir stellen den Nullpunkt des Photometers gegen Luft ein. Zur Kontrolle werden die Extinktionen der trockenen, leeren Küvette und der Dithizonlösung gemessen. $\mathrm{Da}$ die Dithizongebrauchslösung und in geringerem Maße auch das Tarnpuffergemisch keine auf die Dauer konstanten Lösungen darstellen, empfiehlt es sich, bei jeder Bestimmungsteihe folgenden Faktor neu zu bestimmen:

$$
\mathrm{F}=\frac{\text { KonzentrationStandard }}{\text { Extinktionstandard }- \text { Extinktion }{ }_{\text {Leerwert }}} \mu \mathrm{g} / 100 \mathrm{ml}
$$

Die Serumzinkwerte ergeben sich dann aus den gemessenen Extinktionen nach folgender Formel in $\mu \mathrm{g} / 100 \mathrm{~m} l$ :

Konzentration Zinkserum $=$ F $\cdot$ (Ext.Serunt - Ext.Leerwert)

Benötigte Lösungen

1. 1N Salzsäure

2. $3 \mathrm{M}$ Trichloressigsäure 


\section{Die spinale Ossovenographie}

Eine diagnostische Methode zur Erkennung pathologischer Prozesse der Wirbelsäule und des Spinalkanales

Groß-Oktav. 123 Seiten. Mit 122 Abbildungen und 11 Tabellen. 1969. Plastik flexibel etwa DM 36,-

Im Gegensatz zu den in der cerebralen Diagnostik dominierenden angiographischen Verfahren werden die spinalen Gefäße bisher weitgehend vernachlässigt. Die Möglichkeit, das ausgedehnte Venensystem der Wirbelsäule und des Spinalkanales durch eine einfache Methode sichtbar zu machen, ist zwar seit 1952 bekannt, ihr wurde jedoch wenig Beachtung geschenkt. Die engen Beziehungen der Venensysteme zum Rückenmark und seinen Häuten sowie den austretenden Nervenwurzeln einerseits und zur Wirbelsäule andererseits ermöglichen es, pathologische Prozesse, die sich in unmittelbarer Nachbarschaft oder an den Venen selbst abspielen, sicher zu erfassen. Die Einfachheit der Untersuchungsmethode - Injektion von Kontrastmittel in einen Dornfortsatz oder einen Wirbelkörper im Halsbereich - sowie die fehlende Belastung des Patienten, machen sie zu einer wichtigen diagnostischen $\mathrm{Maßnahme,} \mathrm{auf} \mathrm{die} \mathrm{nicht} \mathrm{mehr} \mathrm{verzichtet}$ werden sollte.

Der Verfasser hat seine reichen, anhand eines großen Untersuchungsmaterials gesammelten Erfahrungen mit der spinalen Ossovenographie in einer Monographie niedergelegt. Neben einer ausführlichen Literaturübersicht und Wiedergabe der von ihm gehandhabten Untersuchungstechniken werden Anatomie und Physiologie der Venensysteme sowie das normale Phlebogramm der einzelnen Wirbelsäulenabschnitte besprochen. Die erhobenen Befunde bei den verschiedenen Krankheitsbildern der Wirbelsäule und des Spinalkanales (u. a. Osteochondrosen einschließlich Bandscheibenvorfälle, Spondylolystesis, destruierende Wirbelsäulenprozesse verschiedener Genese, traumatische Veränderungen, epi- und intradurale raumfordernde Prozesse, spinale Angiome, entzündliche Veränderungen) nehmen ebenso wie die Diskussion über den Wert und die Aussagekraft der Methode - auch im Vergleich zu myelographischen Untersuchungeneinen breiten Raum ein. Indikation, Kontraindikation, Komplikationen und Grenzen der Methode werden abgehandelt. Zahlreiche Abbildungen und Tabellen veranschaulichen und unterstreichen die Ausführungen. Eine diagnostische Lücke in der spinalen/vertebralen Diagnostik dürfte damit geschlossen sein.

Priv.-Dozent Dr. med. Heinzgeorg Vogelsaing ist Leiter der Neuroradiologischen Abteilung an der Neurochirurgischen Universitäts-Klinik Gießen.

Walter de Gruyter \& Co : Berlin
Wertvolles Fachbuch

商

\section{Strahlenchemie}

\author{
Grundlagen - Technik - Anwendung
}

Herausgegeben von Prof. Dr. K. Kaindl und Prof. Dr. Dr. E. H. Graul unter Mitarbeit von Dipl.-Ing. H. Bauer, Dr. N. Getoff, Dr. G. R. A. Johnson, Dr. O. F. Olaj, Dr. E. Proksch, Dr. H. Sorantin und Dipl.-Ing. N. Weidinger

645 Seiten. Mit 236 Abbildungen und 95 Tabellen. Kunststoffeinband mit Schutzumschlag 92,- DM

Das Buch gibt einen Überblick über die Grundlagen der Wechselwirkung Strahlung/Materie, der Besprechung der zur Verfügung stehenden Strahlenquellen, der Dosimetrie, der Strahlenwirkung auf anorganische und organische Stoffe, der Wirkung von Strahlung auf Katalysatoren sowie der Möglichkeiten und der Wirtschaftlichkeit industrieller Strahlenanlagen.

Aus dem Inhalt: Definition und Abgrenzung - Historische Entwicklung - Strahlung und Materie - Strahlenarten Allgemeine physikalische Maßsysteme und Umrechnungsfaktoren - Allgemeine physikalische Konstanten Definitionen - Einheiten und Umrechnungsfaktoren aus der Atomphysik-Grundlagen zur Berechnung der Dosisleistung von $\alpha$-Strahlenquellen - Korpuskularstrahlen Photonenstrahlen - Dosimetrie - Strahlenschutz - Strahlung und Materie - Strahlenarten - Strahlenquellen Nukleare Strahlenquellen - Maschinen zur Strahlenerzeugung - Chemische Dosimetrie - Flüssige Dosimetersysteme - Feste Dosimetersysteme - Gasförmige Dosimeter - Strahlenchemie des Wassers - Strahlenchemie wässeriger Lösungen organischer Stoffe - Strahlenchemie der Polymere - Die Bildung von Hochpolymeren durch energiereiche Strahlung - Strahlungseinwirkung auf feste Polymere - Radiolyse organischer Reaktorkühlmittel - Strahlenchemie gefrorener Lösungen - Einwirkung von Strahlung auf anorganische Festkörper - Strahlenwirkung auf Katalysatoren - Oxidische Katalysatoren - Markierte Katalysatoren - Metallische Katalysatoren - Anwendung von bestrahlten Katalysatoren - The Radiation Chemistry of Inorganic Gases Introduction - Theoretical - Experimental Methods The Radiation Chemistry of Some Inorganic Gaseous Systems.

$\mathrm{Zu}$ beziehen durch Buchhandlungen im In- und Ausland, andernfalls durch den Verlag.

Auf Anforderung übersenden wir Ihnen gern unseren Spezialprospekt sowie unseren Katalog "Chemie, Chemische Technik, Makromolekulare Chemie, Kunststoffe, Brandschutz, Erdöl und Erdgas“.

\section{Dr. Alfred Hüthig} Verlag GmbH

Heidelberg

Mainz

Basel 


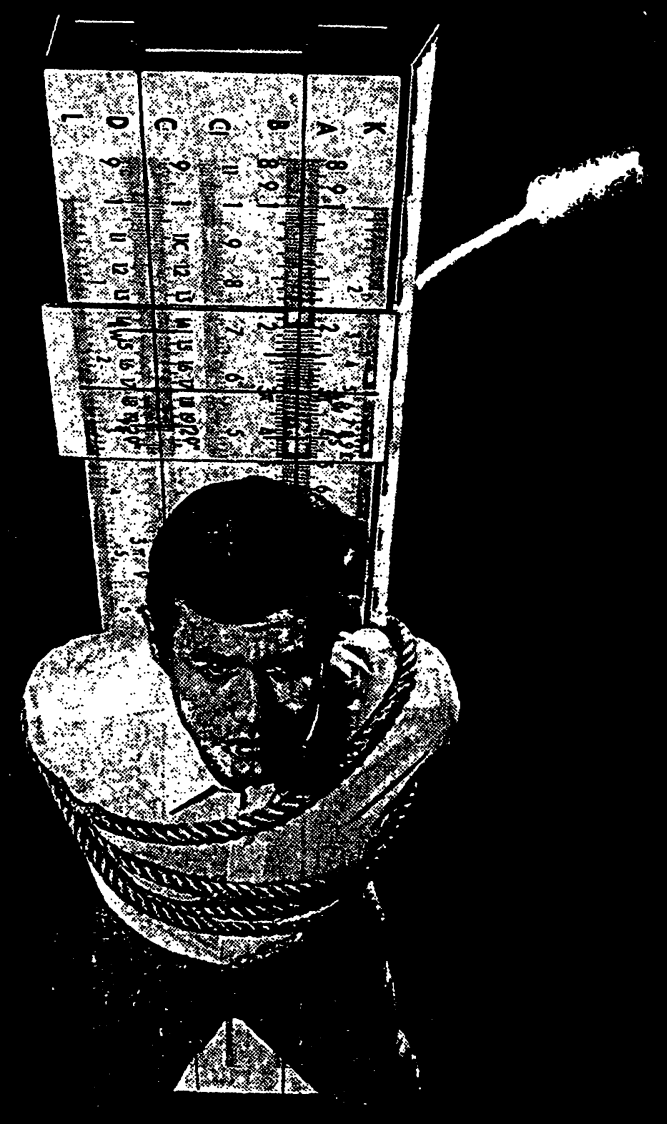

Deutschlands Wissenschaftler, Ingenieure, Techniker, Konstrukteure, Statiker, Architekten fordern:

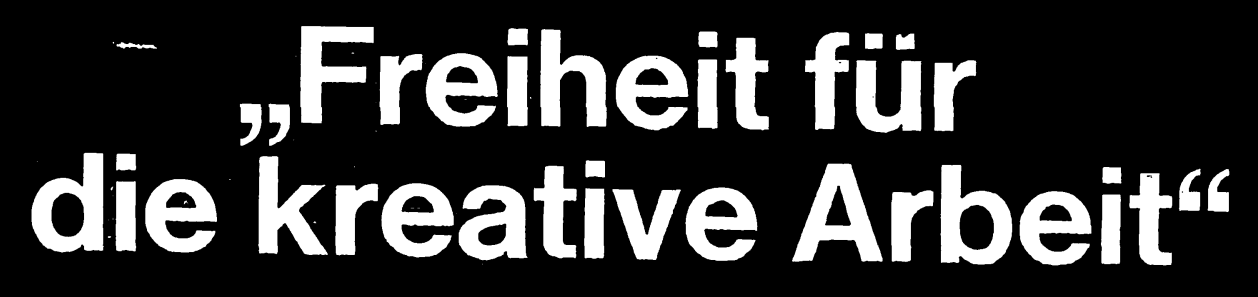




\section{B Programma 101}

\section{effreit Sie}

\section{im Routine-Rechnen!}

Irauchen keine Logarithmentafeln.

Funktionstabellen, keine Rechen-

i. hinen mehr. Wenn Sie Daten und

romationen brauchen, stehen sie Ihnen

therfur Verfügung. Ihre Arbeit wird nicht

Ubrochen. Sie sparen Zeit. Sie sind

eliver. Sie sind

,
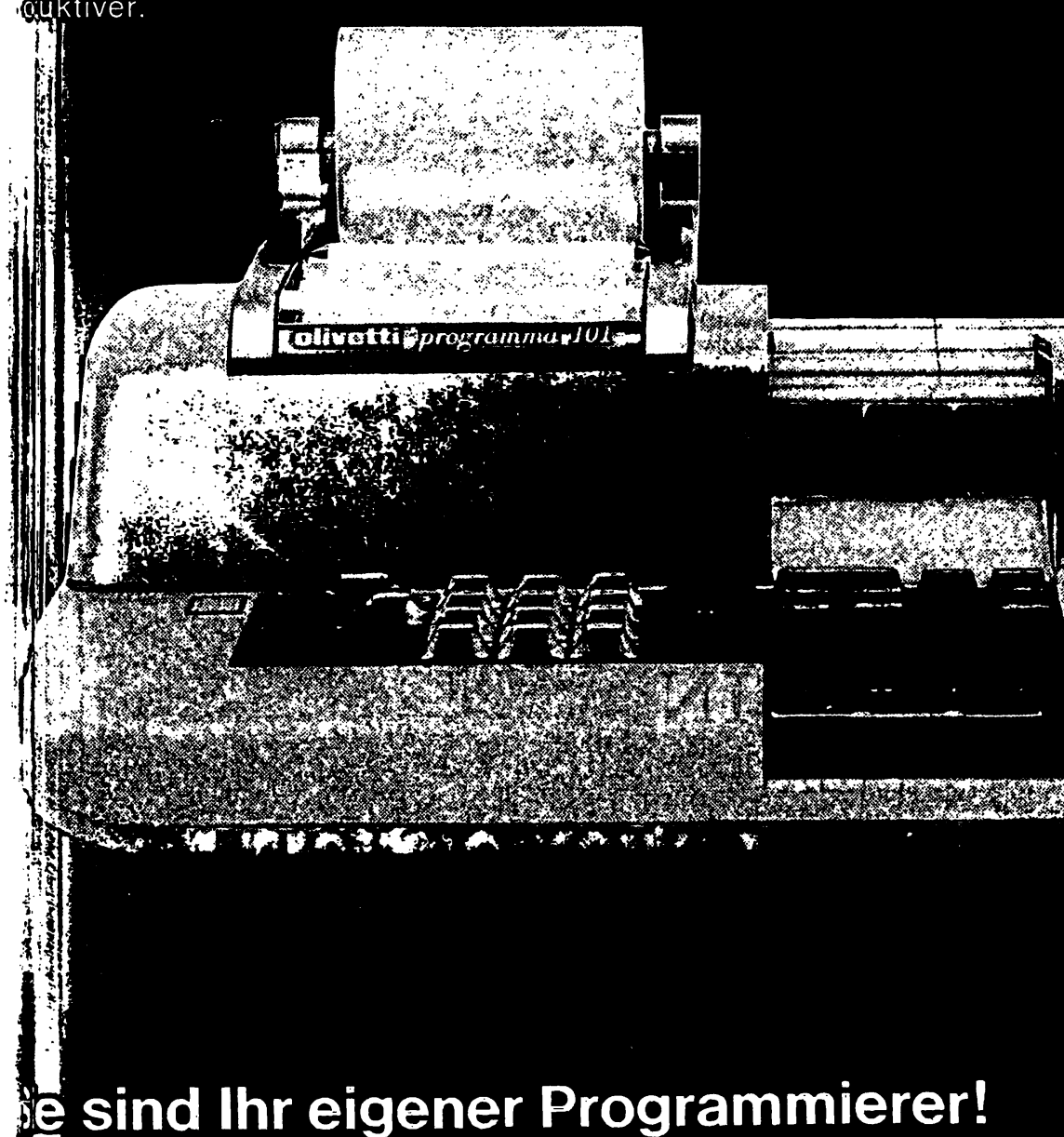

\section{Programma 101 - ein Computer maßgeschneidert für Ihren Arbeitsplatz}

Der Weg zum Rechenzentrum, der sowieso nur sehr umfangreichen Rechenoperationen lohint bleibt Ihnen erspart. Ihr Computer steht dort wo wer

gebraucht wird: an Ihrem Arbeitsplatz. Obwôhl nur so groß wie eine elektrische Schreibmaschine,

ist die Programma 101 ein echter Computers sie rechnet elektronisch, führt einen Rechenablauf selbständig aufgrund gegebener Programme durch,

trifft selbständig logische Entscheidúngen; billdet auf dieser Grundlage Schleifen'spelchert

Programme und Daten extern und finterno

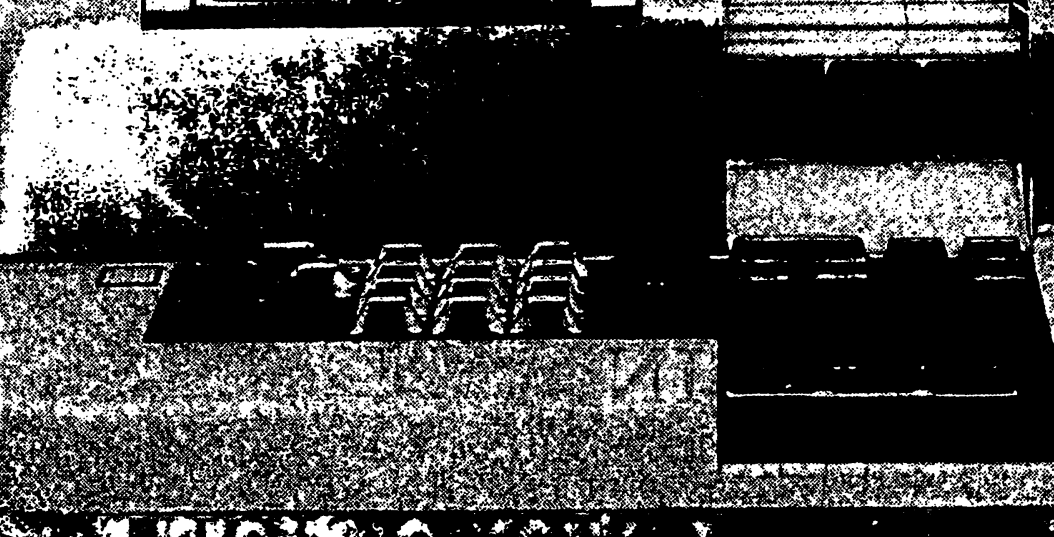

1.
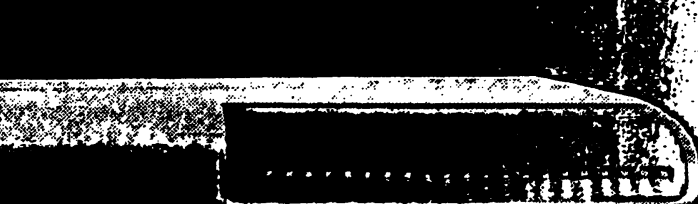

1

\section{sind Thr eigener Programmierer!}

Metti. oder erstellen Sie es selbst. Ein Knopfdruck - und Sie sind jederzeit in der

aje selbst zu programmieren. Ohne. Zusatzgerät. Ohne spezielle Computer-

Whe. Füttern Sie den Compuler mit Ihrem Programm, tasten Sie die variablen

drité über die Zehner-Normtaslalur ein, und geben Sie den Startimpuls: mit

W'tronischer Geschwindigkeit rechnet, entscheidet, druckt, speichert und

Wjistriert Ihr Tischcomputer für Sie. Und das für weniger als 15000 DM.

tilén Sie mehr über die Programma 101 wissen?

ricken Sie den Coupon ein!

\section{Olivetti stellt Ihnen über 2000 Programme für folgende Fachgebiete bereit:}

ISN Mathematik, Medizin, Chemie, Elektrotechnik, Maschinenbau

Apparatebau, Feinmechanik, allgemeine Statistik, Statik 


\section{Handbuch des Diabetes mellitus}

\section{Pathophysiologie und Klinik}

Herausgegeben von Professor Dr. ERnst F. Pfeiffer, Ulm/Donau

\section{Band I}

XXXI / 964 Seiten mit 178 zum Teil farbigen Abbildungen und 41 Tabellen

Leinen 290,-DM

\section{Band II}

erscheint im Laufe des Jahres 1969. Etwa 1000 Seiten mit zahlreichen Abbildungen

Leinen etwa 290,- DM

Bezieher des Bandes I

erbalten den Band II zu einem um 20\% ermäßigten Vorbestellpreis

\section{NEUERSCHEINUNG}

\begin{abstract}
Charakteristik des Werkes
Dieses „Handbuch des Diabetes mellitus“ entspricht nur nach Umfang und Titel dem klassischen Handbuchbegriff, nicht jedoch nach Ausbau und Inhalt. Der Herausgeber hat es verstanden, in zwei Bänden einerseits Theorie und Praxis der rapide, fortschreitenden Diabetesforschung, andererseits Atiologie, Pathogenese, Diagnose und Therapie der menschlichen Zuckerkrankheit zusammen mit führenden internationalen Diabetologen in Deutsch oder Englisch umfassend und doch konzise zu erörtern.

In dem vorliegenden ersten Band werden nach einer als Einleitung verfaßten Besprechung der wechselnden Anschauungen über Ätiologie und Pathogenese der Zuckerkrankheit in drei Hauptabschnitten die Morphologie und Physiologie der Langerhansschen Inseln; der Intermediärstoffwechsel und seine Regulation sowie der spontane und experimentelle tierische Diabetes von 43 kompetenten Autoren erörtert.
\end{abstract}

\section{J. F. LEHMANNS VERLAG MÜNCHEN}

\section{BULLETIN \\ DE LA SOCIÉTÉ DE CHIMIE BIOLOGIQUE}

(„Berichte der Gesellschaft für biologische Chemie“)

Unter Mitwirkung des

"CENTRE NATIONAL DE LA RECHERCHE SCIENTIFIQUE“

(National-Centrum für wissenschaftliche Forschung) veröffentlicht

R. PERLES

Hilfs-Generalsekretär

\author{
J. E. COURTOIS \\ Generalsekretār
}

Y. RAOUL

Hauptredakteur

Sekretariat und Redaktion

4, avenue de l'Observatoire, Paris (6 $\left.6^{c}\right)$

Herausgeber:

Masson et $C_{r E}, 120$, Boulevard Saint-Germain, Paris (6 ${ }^{\circ}$ )

Der „Bulletin de la SociÉtÉ de ChIme Biologrque“ veröffentlicht jährlich 11 Hefte; diese enthalten die Arbeiten der französischen Biochemiker, welche der "SocrÉTÉ DE CHIMIE BIOLOGIQUE“ (Gesellschaft für biologische Chemie) angehören.

Abonnementspreis 1969:

Frankreich und „Franc-Zone“ . . 150 francs

Belgien . . . . . . . . 1684 belges

Andere Länder ... . . . . 165 francs 
Beide Gebrauchslösungen werden dureh Verdünnen der konzentricrten, redestillicrten Säuren mit hidest. Wasser horgestellt und in i,inkfrcien Polyäthylen-Uberlaufflaschen aufbewahrt. Benutzt wurden Trichloressigsäure p. a. (Merck) und Salysãure p. a. (rauchend, Mcrck) nach Redestillation.

\section{Dithi:on-Stammliosung}

$0,1 \mathrm{~g}$ Dithiysen p. a. (Merck) werden in $150 \mathrm{~m} / \mathrm{CCl}_{4}$ (dithizongeprüft, Merck) in eincm $200-\mathrm{m} /$-Scheidetrichter durch $10 \mathrm{Min}$. Schütteln gelöst; anschlicßend wird in cinen $500 \mathrm{~m} /$ Scheidetrichter filtricrt. Nun gibt man $100 \mathrm{~m} / 0,075 \mathrm{~N} \mathrm{NH}_{4} \mathrm{OH}$ (ultrarcin, Mcrck) hinะu und schüttelt 1 Min. Das jetzt in der wäßr. Phase gelöstc Ammoniumdithizonat wird gesammelt, dic organische Phase noch \%wcimal mit jeweils $100 \mathrm{~m} / \mathrm{NH}_{4} \mathrm{OH}$ ausgeschüttelt. Dic gesammelten wäßr. Phasen werden dreimal mit je $2 \mathrm{~m} / \mathrm{CCl}_{4}$ gewaschen, um etwaige Verunteinigungen zu entfernen. Anschließend werden $200 \mathrm{~m} / \mathrm{CCl}_{4}$ hin\%ugegeben und mit $10 \mathrm{ml}$ $1 \mathrm{~N} \mathrm{H}_{2} \mathrm{SO}_{4}$ p. a. (Mcrck) angesäucrt. Das jet \%t in der Tetrachlorkohlenstoffphase gclöstc Dithizon wird gesammelt, dic wäß3r. Phase verworfen. Diese Reinigung des Dithizons wird mehrfach durchgeführt und abschlicß3end dic Dithieon/ $\mathrm{CCl}_{A}-\mathrm{Lös}$ sung mit $100 \mathrm{~m} /$ bidest. Wasser gewaschen. Darauf wird sie 1 Woche unter LichtabschlufS in dic Kühltruhe gestcillt und anschlieljend nochmals filtrict, um evtl. vorhandencs Wasser (Eis) oder ausgefallenes Dithizson zu entferncn. Dic nun gebrauchsfertige Stammlösung wird unter Jichtabsehluß3 in der Kühltruhe aufbewahrt und ist ctwa 2 Jahre halthar.

\section{Dithivon-Gchrauchslösung}

$10 \mathrm{~m} /$ Stammlösung werden in cincm 100 -m/-Meßkolben mit $90 \mathrm{~m} /$ $\mathrm{CCl}_{1}$ gemischt und in einc schwar\% verkleidete Flasche gefüllt. Diesc Jösung hält sich bei Aufbewahrung im Kühlschrank etwa 3 Wochen.

\section{Tarn-Puffer-Gcmisch}

Der 'Tarnpuffex hat dic Aufgabe, bei den gegebenen Bedingungen (pH, Maskicrungsmittcl) dic Reaktion anderer Spurcnclemente mit Dithizon \%u verhindern. Erfahrungsgemäß hat sich für die Festlegung der notwendigen Verdünnung der T'arnpuffer-Substan/cen der folgende Weg als am einfachsten erwiesen:

300 g Natriumacctat (ultrarcin, Merck) werden mit bidest. Wasser zu ctwa $650 \mathrm{~m} /$ gelöst und mit $2,5 \mathrm{~m} /$ Ejscssig (ultrarcin, Mcrck) versctzt, worauf sich pH 6,9-7,0 cinstcllt. $60 \mathrm{~g}$ Natriumthiosulfat (wasscrhaltig, ultrarcin, Mcrck) werden mit bidest. Wasser \%u etwa $150 \mathrm{~m} /$ gelöst. Beide Jösungen werden vermischt. Diese lösung wird nun solange mit bidest Wasser verdünnt, bis sich bei der folgenden Probe pH 5 cinstcllt: $350 \mu /$ Tarnpuffer $+200 \mu /$ hidest. Wasser $+100 \mu / 1 \mathrm{~N} \mathrm{HCl}+50 \mu / 3 \mathrm{M}$ Trichlotessigsäurc. $100 \mathrm{~m} /$ der so gewonnenen Iösung werden in eine zinkfreic Polyãthylenflasche gefüllt und mit $0,2 \mathrm{~g} \mathrm{KCN} \mathrm{p.} \mathrm{a.} \mathrm{(dithizongeprüft,} \mathrm{Merck)}$ versct/t; dicse gebrauchsfertige Lösung ist 4 Wochen haltbar.

\section{Zink-Standardlösung}

Zur Herstellung der Stammlösung wird ein gewogenes Zinkkorn (Zink, gekörnt, Mcrck) in mit Salzsäurc p. a. angesaucrtcm bidest. Wasser gelöst und kromplexumetrisch mit Titriplex geprüft. Wir benut $\%$ ten eine Stammlösung von $5000 \mu \mathrm{g} / 100 \mathrm{~m} /$, aus der alle 3 Monate cine Standardlösung von $100 \mu \mathrm{g} / 100 \mathrm{~m} /$ hergestcllt wurdc.

\section{Reinigung der Gerätce}

Dic Kanülen werden $1 / 2$ Std. in bidest. Wasser gekocht und anschliefßnd sterilisiert.

Dic Polyäthylenrïhrchen und Pipettenspityen des Mikroprogramms der Fa. Nethclex \& Hinะ häben sich als nicht genügend sauber erwiesen, auch wenn sic nach dem Verfahren gereinigt werden, das wir bei den Röhrehen für die Mikroeisenhestimmung verwenden (4).

Wir verwenden daher folgendes Reinigungsverfahren: Btwa 400 Röhrehen werden in einem 4 / Schliffrundkolben mit 96pros.. vergälltem Alkohol, in dem 2 Spatelspitzen Dithizon gelöst werden, 4 Stdn. am Rückflußkühler gekocht, nach Abkühlen dekanticrt, mindestens dreimal mit Methanol p. a. gründlich ausgewaschen und darauf 1 Std. mit Methanol am Rückflußkühler gckocht. Dann wird gründlich dekanticrt und im Trockenschrank bei $40^{\circ}$ getrocknct. Eine eventucll auftretende geringe Verfärbung der Röhrehen ist belanglos. Ebenso verfährt man mit den Spit\%en und anderen Kunststoffgeräten.

\section{Zinknachweis im Urin}

Dic Reinigung der Glasröhrchen und die Vorbercitung des Urins erfolgt genau wie bei der Mikromethode zur Eiscnbestimmung (4). Man verfährt dann wie folgt: In je 2 graduicrte Glasröhrchen $(10 \mathrm{~m} /)$ werden je $1 \mathrm{~m} /$ bidest. Wasser b\%w. Zinkstandard h\%w. Urin gefüllt. Unter kurzem Umschütteln werden in jedes Rijhrehen $200 \mu / \mathrm{H}_{4} \mathrm{SO}_{4}$ kon\%. p. a. (Morck) gegeben, anschlicßand $200 \mu \mathrm{l}$ Perchlorsäure p. a. 35pro\%. (Merck). Alle Röhrchen werden schräg in cin heiles Sandbad gesteckt, bis alles Wasser abgedampft ist, dann senkrecht ticf vergraben. Es wird 3 Stdn. bei mäßigem Sicden verascht. Nach dem Abkühlen werden unter jewcils kur\%em Umschüttcln nacheinander folgende Reagenzicn in der angegebenen Reihenfolge zugegeben:

$1 \mathrm{~m} /$ bidest. Wasser

$50 \mu /$ Bromkresolgrün-Lüsung

tropfenweise $\mathrm{NH}_{3}$ kon\%. (ultrarcin Merck) bis \%um Umschlag nach blau

$200 \mu /$ Ejscssig (ultrarcin, Mcrck)

$800 \mu /$ Tarnpuffergemisch

Dic lösung wird mit bidest. Wasser auf $3 \mathrm{~m} /$ ergän\%t.

Von diescr aufgefuillten Jösung werden je $200 \mu l$ in Polyäthylenröhrchen pipetticrt, $300 \mu /$ Dithizonlösung hin\%ugegchen. Es wird wic bei der Scrumzinkbestimmung weiterverfahren.

\section{Ergebnisse}

Prüfung der Serumøink-Methode

\section{Feblerbreite der Faktorbestimmung}

Wegen seincr Empfindlichkeit gegenüber Jjehtcinwirkung und Tempcraturschwankungen stcllt dic verwandte Dithizonlösung keinc über längerc Zeit in ihrer Kon\%entration und Farbe konstante Lösung dar; cbenso ist der Gchalt des Tarnpuffers an KCN nicht konstant \%u halten. Daher ist das Arbeiten mit einem cinmal bcstimmten Bestimmungsfaktor zur Bestimmung des Zinkgehaltes aus der Extinktion, wie es bei der Eisenund Kupferbestimmung möglich ist, unะweckmäßjg. Es muß vielmehe bej jeder Bestimmungsreihe der Faktor neu bestimmt werden. In diesen gehen alle Ungenauigkeiten der oben genannten Jösungen durch die Berücksichtigung der J_eerwertc ein. Wir haben untersucht, wic wcit trot $\%$ der in gewissem Maße immer erfolgenden Schwankung der. Paktoren zwischen mehreren Mc $3-$ reihen eine \%uverlässige Zinkbestimmung möglich ist. In 6 Fällen wurden dabei nach der angegebenen Vorschrift Extinktionen von Jeerwerten und jeweils 2 verschicdenen, gegebencen Standardlösungen bestimmt, mit jedem Standard cin Faktor crrechnct und mit dicsem Paktor die Kon\%entrationen des jeweils 2. Standards ausgerechnet. Das Ergebnis zeigt Tabelle 1. Es finden sich bei der Bestimmung Abweichungen vom bekannten Wert bis \%u maximal $1,5 \%$, im Durchschnitt von $1 \%$.

\section{Jeblerbreite bei Mebrfacbbestimmungen int gleichen Serum}

Es wurden 8 Bestimmungsreihen von je eincm Standard $337,5 \mu \mathrm{g} / 100 \mathrm{ml}$, cincm Scrum, dem Serum $+84,5 / \mu \mathrm{g} /$ $100 \mathrm{~m} /$ hinzugcfügtcm Zink, und dem Scrum $+168,5 \mu \mathrm{g} /$ $.100 \mathrm{~m} /$ Zink durchgeführt. Aus den 8 gewonnenen Bestimmungsfaktoren $\mathrm{F}$ wurde cin Durchschnjttsfaktor ermittclt, und mit dicsem dic Zinkkonzentration errechnet. Die Ergcbnisse zcigt Tabelle 2. 
Tab. 1

Streuungsbreite der Zinkbestimmung in Abhängigkeit der jeweils errechneten Faktoren

Anmerkung: Spalte 2 gibt die gewählten Zinkstandardlösungen an (Konzentrationen in $\mu \mathrm{g} / 100 \mathrm{ml}$ ), die Spalten 3 und 4 die Extinktionen von Aeerwert und Standardlösungen, die gemessen wurden, Spalte 5 den Betrag Extinktion Standardlösurig - Extinktion Leerwert, mit dem der Faktor F berechnet wird. Dieser steht, aus dem Mittelwert dieser Beträge (Spalte 6) bestimmt, in Spalte 7 . In Spalte 8 stehen die Konzentrationen (in $\mu \mathrm{g} / 100 \mathrm{ml}$ ), die für die gemessenen Extinktionen eines Standards mit Hilfe des mit dem anderen

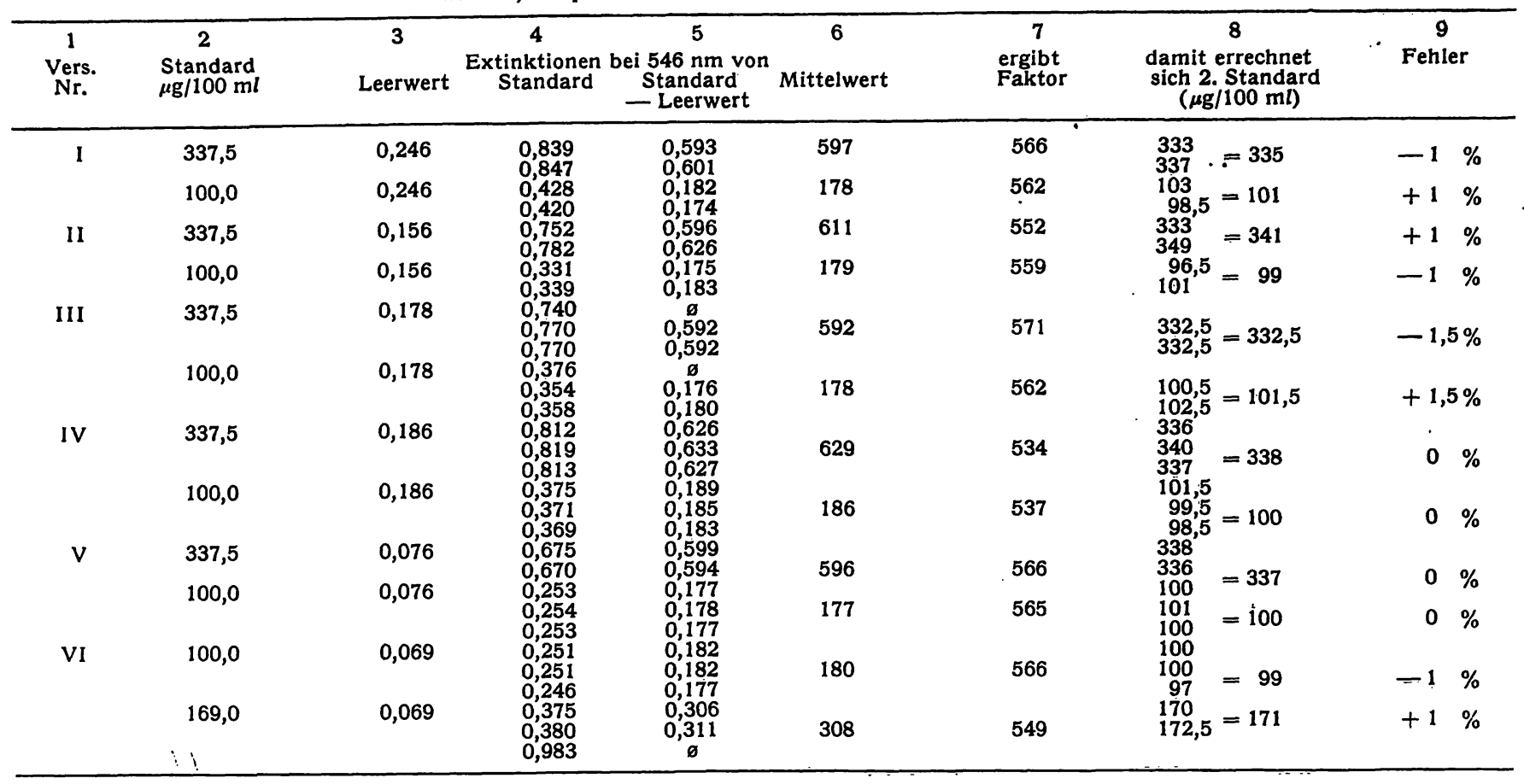

Tab. 2

Streuungsbreite bei Mehrfachbestimmungen (s. Text)

\begin{tabular}{lcc}
\hline Gegebene Lösung & $\begin{array}{c}\text { dafür } \\
\text { gefundener } \\
\text { Mittelwert } \\
(\mu \mathrm{g} / 100 \mathrm{~m} l)\end{array}$ & $\begin{array}{c}\text { mit } \\
\text { Standard- } \\
\text { abweichung } \\
(\mu \mathrm{g} / 100 \mathrm{ml})\end{array}$ \\
\hline Standard $337,5 \mu \mathrm{g} / 100 \mathrm{ml}$ & 337,5 & $\pm 3,4$ \\
$\begin{array}{l}\text { Serum } \\
\text { dem Serum zugegebene Zink- }\end{array}$ & 134 & 4,3 \\
$\begin{array}{c}\text { menge 84,5 } \mu \mathrm{g} / 100 \mathrm{ml} \\
\text { dem Serum zugebene Zink- }\end{array}$ & 81 & 2,6 \\
menge 168,5 $\mu \mathrm{g} / 100 \mathrm{ml}$ & 167,8 & 3,5 \\
\hline
\end{tabular}

Tab. 3

Streuungsbreite der Serumzinkbestimmung bei Verwendung von $0,1 \mathrm{ml}$ Serum

\begin{tabular}{ccc}
\hline Abweichung vom Mittelwert & $\begin{array}{c}\text { Anzahl der } \\
\text { untersuchten } \\
\text { Seren }\end{array}$ & $\begin{array}{c}\text { Prozentuale } \\
\text { Häufigkeit }\end{array}$ \\
\hline $0-5 \mu \mathrm{g} / 100 \mathrm{ml}$ & 234 & $89,3 \%$ \\
$6-10 \mu \mathrm{g} / 100 \mathrm{ml}$ & 17 & $6,5 \%$ \\
über $10 \mu \mathrm{g} / 100 \mathrm{ml}$ & 11 & $4,2 \%$ \\
\hline
\end{tabular}

Tab. 4

Serumzinknormalwerte bei Kindern

\begin{tabular}{lcccc}
\hline Altersgruppe & $\mathrm{n}$ & $\begin{array}{c}\overline{\mathrm{x}} \\
(\mu \mathrm{g} / \\
100 \mathrm{ml})\end{array}$ & $\begin{array}{c} \pm \mathrm{s} \\
(\mu \mathrm{g} / \\
100 \mathrm{ml})\end{array}$ & $\begin{array}{c}\overline{\mathrm{x}} \pm 2 \mathrm{~s} \\
(\mu \mathrm{g} / \\
100 \mathrm{~m} l)\end{array}$ \\
\hline Frühgeborene & 13 & 115 & 22,45 & $70-160$ \\
Neugeborene & 8 & 111 & 16,40 & $78-144$ \\
$1-12$ Monate & 10 & 111 & 14,25 & $83-139$ \\
$1-2,5$ Jahre & 9 & 112 & 15,23 & $82-142$ \\
2,5-5 Jahre & 15 & 111 & 17,26 & $77-145$ \\
$5-12$ Jahre & 22 & 114 & 18,27 & $78-150$ \\
über 12 Jahre & 16 & 109 & 11,44 & $86-142$ \\
\hline
\end{tabular}

\section{Differenz zwischen den Doppelbestimmungen}

Bei einer Reihe von 100 Doppelbestimmungen/ergab sich eine mittlere Differenz zwischen beiden Einzelbestimmungen von $3,5 \mu \mathrm{g} / 100 \mathrm{ml}$. Tabelle 3 zeigt eine Aufstellung von 262 Doppelbestimmungen, gegliedert in 3 Gruppen nach der Streuungsbreite der Doppelbestimmungen. Die erste Spalte gibt die Abweichung der beiden Einzelwerte vom Mittelwert an, die zweite Spalte die absolute Häufigkeit der Ergebnisse in dieser Streuungsbreite, die dritte die relative Häufigkeit in Prozenten.

Bei den zuletzt genannten 11 Seren handelt es sich durchweg um durch Verunreinigungen unbrauchbare Bestimmungen; sie wurden wiederholt. Das Ausmaß der Differenz beider Einzelbestimmungen ist kein 'Gradmesser für die Genauigkeit einer Bestimmung. Von entscheidender Wichtigkeit ist die Kongruenz der Extinktionen bei Leerwert und Standard; wir machen deshalb von diesen jeweils Dreifachbestimmungen.

\section{Normalwerte im Serum}

Zur Bestimmung der Normalwerte wurden unausgelesene Fälle verschiedener Altersgruppen aus dem Krankengut unserer Klinik und Poliklinik herangezogen, soweit sie nicht an Krankheiten erkrankt waren, die

Tab. 5

Vergleich der Zinkausscheidung im Urin an verschiedenen Tagen.

\begin{tabular}{|c|c|c|c|c|c|}
\hline Patient & Datum & $\underset{(\mathrm{m} l)}{\text { Urinmenge }}$ & $\underset{(\mu \mathrm{g} / 100 \mathrm{ml})}{\mathrm{Zn-Konz}}$ & $\underset{(\mu \mathrm{g})}{\text { Urin-Zn/24 Stdn. }}$ & Bemerkungen \\
\hline $\begin{array}{l}\text { Ott. } \\
\text { Ott. } \\
\text { Ott. } \\
\text { Zar. } \\
\text { Umi. }\end{array}$ & $\begin{array}{c}29.9 . \\
30.9 \\
8.1 \text {. }\end{array}$ & $\begin{array}{r}1110 \\
1530 \\
280 \\
970 \\
840\end{array}$ & $\begin{array}{c}87 \\
60,5 \\
326 \\
74 \\
41\end{array}$ & $\begin{array}{l}965 \\
925 \\
910 \\
720 \\
\mathbf{4 8 8}\end{array}$ & $\begin{array}{l}\text { aplast. Anämie, Hämosiderose } \\
\text { Serum Zn um } 150 \mu \mathrm{g} / 100 \mathrm{ml} \\
\text { Fe-Mangelanämie }\end{array}$ \\
\hline
\end{tabular}


bekanntermaßen mit einer Veränderung des Serumzinkspiegels einhergehen. Die Ergebnisse zeigt Tabelle 4.

\section{Zinkgehalt im Urin}

Es wurden 5 Doppelbestimmungen von 24-Stdn.Sammelurinen gemacht. Das Ergebnis zeigt Tabelle 5.

\section{Diskussion der Ergebnisse}

Die allmähliche Alterung der Dithizongebrauchslösung bewirkt eine ständige Ânderung der Extinktion dieser Lösung und damit auch des Leerwertes. Das macht die Benutzung eines einmal bestimmten Faktors F unmöglich. Trotzdem haben die jedesmal neu bestimmten Faktoren keine größere Fehlerbreite als im Durchschnitt $1 \%$, wie Abbildung 1 zeigt. Mehrfachbestimmungen von Seren zeigen keine größeren Standardabweichungen als Messungen von eiweißfreien Standardlösungen (siehe Tab. 2). Dabei ist der "mittlere Fehler" der ermittelten Mittelwerte nicht größer als maximal $1,5 \mu \mathrm{g} / 100 \mathrm{~m} /$. Die mittlere Abweichung der Einzelbestimmungen vom Mittelwert bei unseren Routine-Doppelbestimmungen ist in fast $90 \%$ unter $5 \mu \mathrm{g} / 100 \mathrm{~m} /$ und damit fast gleich den Ergebnissen bei der Mikroeisenbestimmung (4).

Bei den Normalwerten findet sich ein durch alle Lebensalter konstant hoher Serum-Zinkspiegel. Dabei zeigt sich eine gute Ưbereinstimmung mit den bei Erwachsenen von Vikbladh (5), Berfenstam (6), Vallee $(3,7)$, Wollf (8), Prasad (9) und KaHN (10) gefundenen Werten. Als einziger untersuchte Berfenstam den Zinkspiegel auch bei Kindern. Er fand für Kinder ab 5 Jahren den unseren entsprechende Daten; bei zunehmend jüngeren Kindern fand er jedoch einen zunehmend höheren Zinkspiegel. Dabei fallen bei seinen Werten die sehr viel größeren Standardabweichungen auf (z. B. bei 16 Frühgeborerien $\overline{\mathrm{x}}=187 \mu \mathrm{g} / 100 \mathrm{~m}$, $s= \pm 78 \mu \mathrm{g} /$ $100 \mathrm{~m} /$ ). Eine Ausnahme macht seine Angabe für Neu- geborene, die der unseren fast gleicht $(\overline{\mathrm{x}}=125 \mu \mathrm{g} /$ $100 \mathrm{ml}, \mathrm{s}= \pm 33 \mu \mathrm{g} / 100 \mathrm{ml})$. Vielleicht erklärt sich dieser Unterschied dadurch, daß BERfenstam seine relativ großen Blutmengen bei Säuglingen oft nur als Kapillarblut von der Ferse entnehmen konnte, während wir immer Venenblut benutzten. Bei Neugeborenen und Frühgeborenen entnahm BERfENSTAM ebenso wie wir Blut aus der Nabelschnur.

VAllee berichtete, daß nur ein kleiner Teil des täglich ausgeschiedenen Zinks im Urin erscheine; dieser Anteil sei für das Individuum relativ konstant und von der Urinmenge unabhängig (3). $\mathrm{Da}$ alle Literaturangaben eine enorme Schwankungsbreite der Normalbereiche angeben, verzichteten wir auf eine Feststellung eines eigenen Mittelwertes und stellten nur stichprobenweise fest, daß unsere Werte innerhalb dieser Normalbereiche liegen. VAlleE (7) gab bei 14 untersuchten Gesunden einen Mittelwert von $457 \mu \mathrm{g} / 24 \mathrm{Stdn}$. bei einer Standardabweichung von $s= \pm 120 \mu \mathrm{g}$ an, KAHN (3) bestimmte mit der gleichen Methode als Werte $\overline{\mathbf{x}}=500 \mu \mathrm{g} / 24$ Stdn., $s= \pm 250 \mu \mathrm{g}, \operatorname{PrASAD}(5)$ fand bei 9 Patienten einen Urinzinkgehalt von im Mittel $613 \mu \mathrm{g}$ pro Tag mit $\mathrm{s}= \pm 280 \mu \mathrm{g}$.

Voraussetzung für die Erlangung guter Meßergebnisse ist die genaue Einhaltung der Reinigungsvorschriften für die Gefäße und Pipettenspitzen sowie der Lichtabschluß beim Arbeiten mit kleinen Mengen von DithizonGebrauchslösung. Bei Erfüllung dieser Bedingungen erweist sich diese Mikromethode als einfach und zuverlässig und ist ohne weiteres als Routinemethode zu verwenden. Das Überpipettieren der Zinkdithizonat/Tetrachlorkohlenstoffphase in die Mikroküvette macht dabei keinerlei Schwierigkeiten.

Wir danken Frl. B. KroHN und Fr. E. SckLETt für technische Assistenz.

\section{Literatur}

1. Neth, R., H. Schmalfuss und D. Goschenhofer, diese $Z$. 3, 61 (1965). - 2. Inantscheff, G., Das Dithizon und seine Anwendung in der Mikro- und Spurenanalyse. Verlag Chemie GmbH., Weinheim, Bergstraße (1958). - 3. Vallee, B. L., Physiol. Rev. (Baltimore) 39, 443 (1959). - 4. Neth, R., K. H. SCHÄFER, D. GOSCHENHOFER und E. LAACK, Klin. Wochenschr. 41, 1089 (1963). - 5. VIKBLADH, I., Scand. J. Clin. Laborat. Invest. 2, 143 (1950). - 6. Berfenstam, R., Acta paediatr. Suppl. 87 (1952). - 7.
Valieg, B. L., W. E. C. Wacker, A. F. Bartholomay und F. L. Hoch, Ann. Int. Med. 50, 1077 (1959). - 8. WolfF, H. P., Klin. Wochenschr. 34, 409 (1956). - 9. Prasad, A. S., H. H. SANDSTEAD, A. R. Schulert und A. S. El Rooby, J. Laborat. Clin. Med., S. Louis 62, 591 (1963). - 10. KAFN, A. M., H. L. Helwig, A. G. Redeker und T. B. Reynolds, Amer. J. Clin. Path. 44, 426 (1965).

H. H. Hellwege 2000 Hamburg 20 Martinistr. 52 